\title{
Forest logging is associated with shape of males and gynes in the wood ant Formica aquilonia
}

\author{
J. Sorvari ${ }^{1,2}\left(\mathbb{0} \cdot\right.$ M.-K. Haatanen $^{1}$
}

Received: 24 February 2021 / Revised: 24 November 2021 / Accepted: 10 December 2021 / Published online: 17 February 2022

(c) The Author(s) 2022

\begin{abstract}
Environmental stress can affect individual development and fitness in insects. Forest logging is a serious environmental stress for forest-specialist insects, such as the mound-building wood ant Formica aquilonia Yarrow 1955, which builds its nests into forests and is dependent on the nutrition provided by the forest habitat. We studied whether the logging causes such a strong environmental stress that it would be visible in disproportionate growth and shape of young winged wood ant gynes ('queens') and males. We measured head width, thorax width and wing length of 144 gynes and 100 males from 12 nests from six clear-cut areas, 11 nests from unlogged forest stands and 10 nests in clear-cut—forest margins. We observed disproportionate growth of different body parts and allometric growth of wings in both sexes in areas with different logging-induced disturbance. Gynes had larger heads in clear-cut areas and males had narrowest thoraxes in forest clear-cut edges. With an increasing thorax width, the wing length decreases steeper in clear-cuts than in other habitats in gynes and increases steeper in clear-cuts than other habitats in males. It seems that in a strongly disturbed clear-cut environment, the gynes invest the growth of head width. There seems to be a trade-off between the growth of the thorax and wings in gynes but not in males. The altered body shape may be adaptation to clearings caused by storm events of wild fires, but not forest management practices of modern era. Large-headed gynes may be better in a colony take-over, needed for the establishment of new colonies in early succession stage habitats in this temporally social parasitic species. Long-winged males may have better long-range flight ability, and they may thus have better fitness and change to disperse their genes onto new habitats.
\end{abstract}

Keywords Allometry $\cdot$ Body size $\cdot$ Disproportionate growth $\cdot$ Disturbance $\cdot$ Forestry $\cdot$ Wing length

\section{Introduction}

The current era, Anthropocene, is challenging insects, including social insects, with plenty of anthropogenic environmental changes that alter abiotic and biotic factors, such as temperature and nutrition that are known to have potential to affect growth of insects (e.g., Chown and Nicolson 2004). During the development of an insect, different body parts can grow disproportionately due to pathways that may be co-affected by environmental factors such as temperature and nutrition (e.g., Koyama et al. 2013; Lavine et al. 2015).

J. Sorvari

jouni.sorvari@utu.fi

1 Department of Biology, University of Turku, 20014 Turku, Finland

2 Natural Resources Institute Finland, P.O. Box 2, 00790 Helsinki, Finland
This raises a question whether anthropogenic disturbances in nature can affect shape of insects.

Monomorphic insects and other monomorphic animals tend to develop so that the proportional relationships are preserved between small and large individuals. This is called isometric scaling, and it is opposed by allometric scaling when there is any deviation from isometry. An excellent example of colony-level allometry is polymorphic ants with morphologically different worker castes, e.g., leafcutter ants, army ants and fire ants that have large-headed 'soldiers' (Feener et al. 1988; Tschinkel et al. 2003; Araujo and Tschinkel 2010).

Typically, signs of habitat-related disturbed growth are explored by measuring body size or fluctuating asymmetry of body parts (e.g., Rabitsch 1997; Grześ et al. 2015; Nunes et al. 2015; Ivanković Tatalović et al. 2020) or ornaments (e.g., Skaldina and Sorvari 2017; Skaldina et al. 2020); but to our knowledge, studies concerning habitat changeinduced allometric scaling are lacking. 
In Finland, forest clear-cutting is the most common forest renewal method (Vaahtera 2019). For the wood ants of the Formica rufa group, removal of trees means food resource limitation as the main food sources, aphids, are reared in trees and insect prey is also mainly preyed in trees (Lenoir 2003). The decrease in food availability after clear-cutting has reduced body energy reserves of the wood ant Formica aquilonia Yarrow, 1955 (Sorvari and Hakkarainen 2009; Sorvari et al. 2011). In addition, both the micro-climate and uppermost soil layers may become drier in clear-cut areas (Keenan and Kimmins 1993), which alter the temperature and humidity regulation of the mound nests of wood ants (Sorvari and Hakkarainen 2009; Sorvari et al. 2016).

Decreased food availability and malfunction in nest temperature and humidity regulation is detrimental to wood ants and is likely causing the observed nest abandonment process in clear-cuts (Sorvari and Hakkarainen 2007a). Not all nests are abandoned soon after clear-cutting; thus, the poor environment can cause physiological stress to growing ant larvae and pupae, which could affect the adult body size and size and allometric scaling of different body parts. Accordingly, a significant decrease in body size measured as head width was found in F. aquilonia workers grown in clear-cut areas (Sorvari and Hakkarainen 2009). However, in gynes (unmated queens), this effect was not found in an earlier study by the authors (Haatanen and Sorvari 2013) raising the question whether the effect of habitat degradation could be measurable in other body parts or in the allometric scaling of the body parts. This could be a sign of ants trying to adapt to the new environmental conditions.

The objective of this research was to study (i) whether forest clear-cutting is associated with size of head width, thorax width and wing length, (ii) whether the body parts are developing allometrically, and (iii) whether the possible allometric scaling is associated with the strong decrease in habitat quality in gynes and males of $F$. aquilonia.

\section{Materials and methods}

Formica aquilonia is the most common red wood ant in northern European boreal forests (e.g., Collingwood 1979; Kvamme 1982; Punttila and Kilpeläinen 2009; Sorvari 2021). It is a typical species in sparse to medium density mature forest stands and forest edges from Scotland to Siberia (Collingwood 1979). It is a highly polygynous (multiple queens) and polydomous (multiple nests) species, with large nest mounds containing over a million workers and hundreds of queens (Pamilo 1982).

To test our hypotheses, recently produced 144 gynes and 100 males of $F$. aquilonia were collected in the spring of 2001 from forests (11 nests, eight forest stands), and clear-cut areas and their forest-clear-cut margins, here forth 'forest edges' (12 nests in clear-cuts and 10 nests in forest edges in six clear-cut areas), in Jyväskylä, Finland $\left(62^{\circ} 15^{\prime}, 25^{\circ} 46^{\prime}\right)$. One to two nests were sampled from each study stand. All study stands, also clear-cuts prior to the logging, were bilberry (Vaccinium myrtillus L.) growth forests dominated by over 70-year-old Norway spruces (Picea abies L.). Logging has occurred 1-2 years prior to the sampling and the clear-cuts were treeless and planted with one-year-old Norway spruce saplings. All forest interior nests were over $50 \mathrm{~m}$ distance from the nearest forest edge. Clear-cut nests were all within the borders of logged area. Forest edge nests were 1-15 $\mathrm{m}$ away from the clear-cut margins inside the forest.

Individuals were stored in $96 \%$ alcohol until characters were measured in the year 2012. The measured characters were thorax width between wing bases, head width above compound eyes, and wing length (TW, HW, WL, respectively). The WL was measured over three wing cells from the junction of veins $1 \mathrm{M}$ and $1 \mathrm{Cu}$ to the junction of veins 5RS and $\mathrm{R}$ from both left and right forewing. The mean of the left and right wing-length measurement was used as the WL. The measurement accuracy did not allow us to measure fluctuating asymmetry in WL. The measurements were made using microscope photos taken with Olympus SZ40 microscope combined with Deltapix Invenio 3S 3 Mpix digital camera using $12 \times(\mathrm{TW}), 20 \times(\mathrm{WL})$, and $35 \times(\mathrm{HW})$ magnification, exposure $45 \mathrm{~ms}$ and illuminance 2800 lx. The measurements were made using image analysis software (ImageJ) in mm scale.

We adopted similar method than in Tschinkel et al. (2003) and created size-free estimate of shape using a logarithm of the ratio of two measurements (WL/TW, $\mathrm{HW} / \mathrm{TW}$ ) and then regressed these log-ratios against the logarithm of other body size measurements (TW, HW). Head width (HW) and wing length (WL) were regressed as logarithms of ratios with thorax width (TW) or HW using formula $\log y=b+\mathrm{a}[\log (x / y)]$. If a slope is different from zero by $t$-test, it indicates that the shape is allometric, i.e., it changes with body size (Mosiman and James 1979; Tschinkel et al. 2003).

Gynes and males of $F$. aquilonia are morphologically very different in shape, thus, the majority of morphological analyses between sexes is useless. Statistical analyses were performed using linear mixed model analyses for between-habitat comparisons and linear regression models for allometry in statistical software SAS version 9.4 (SAS Institute, Cary, NC, USA). All means presented are estimated marginal means of models accompanied with $95 \%$ confidence limits. Nest of origin was used as a random factor in the analyses with Kenward-Roger approximation for degrees of freedom. 


\section{Results}

\section{Head and thorax width}

In gynes, the head width (HW) was similarly associated with thorax width in all three habitat types (interaction term TW $\mathrm{X}$ habitat type: $F_{2,134}=1.93, P=0.15$ ). HW was not significantly associated with thorax width $\left(F_{1,137}=1.91, P=0.17\right)$, but the HW differed between habitat types $\left(F_{2,16.9}=4.99\right.$, $P=0.020)$. The gynes from forest nests had significantly smaller HW than the clear-cut gynes and marginally nonsignificantly smaller HW than that of forest edge gynes; forest edge gynes and clear-cut gynes did not differ significantly from each other (Tukey's tests for pairwise differences, forest vs. clear-cut: $P=0.034$; Forest vs. forest edge: $P=0.055$, clear-cut vs. edge: $P=0.78$; Fig. 1 ).

In males, the HW was similarly associated with TW in all three habitat types (interaction term TW X habitat type: $\left.F_{2,83.4}=1.89, P=0.16\right)$. HW did not differ between habitat types $\left(F_{2,13.2}=0.13, P=0.87\right)$, but unlike in gynes, the HW increases with increasing TW $\left(\mathrm{R}^{2}=0.27, F_{1,85.7}=14.52\right.$, $P=0.0003$ ).

The TW did not differ significantly between habitat types in gynes, whereas in males, there was a marginally non-significant difference (gynes: $F_{2,21.1}=1.17, P=0.33$; males: $\left.F_{2,10.6}=3.87, P=0.055\right)$. The forest edge males had significantly smaller TW than in the males from

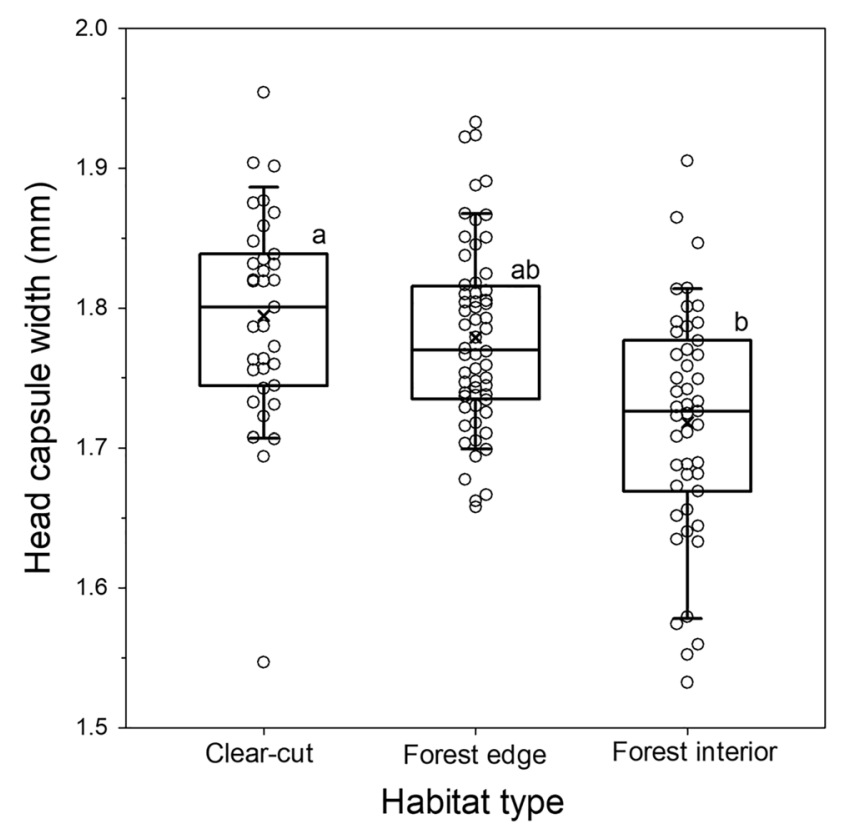

Fig. 1 Head width of gynes in clear-cuts, forest edges (clear-cut margins) and forest interiors. Data points are jittered in order to avoid overlapping. Different letter above symbols indicates significant pairwise difference (Tukey's test $P<0.05$ ) clear-cuts, other pairwise comparisons were non-significant (forest edge vs. clear-cut: $P=0.049$, forest edge vs. forest: $P=0.20$, clear-cut vs. forest: $P=0.39$; Fig. 2 ).

\section{Length of wings}

In gynes, the wing length (WL) did not differ between the habitat types $\left(F_{2,18.5}=0.55, P=0.59\right)$. However, it was differently associated with TW between the tree habitat types (interaction term TW X habitat type: $F_{2,133}=5.59$, $P=0.0047)$. Predicted WL decreased with an increasing TW in clear-cuts, whereas the association was nonsignificant in forests and forest edges (clear-cuts: $\mathrm{R}^{2}=0.69$, $F_{1,32.5}=10.85, P=0.0024$; forest edges: $R^{2}=0.05$, $F_{1,58.8}=0.01, P=0.91$; forest interiors: $R^{2}=0.36$, $F_{1,40.7}=1.69, P=0.20$; Fig. 3). Similarly, in males, the WL did not differ between the habitat types $\left(F_{2,15.6}=1.28\right.$, $P=0.31$ ), but it was differently associated with TW between habitat types (interaction term TW X habitat type: $F_{2,90.8}=4.69, P=0.012$ ). Predicted WL increased with an increase in TW in clear-cut males, whereas the associations were nonsignificant in forests and forest edges (clear-cuts: $R^{2}=0.55, F_{1,14.2}=32.78, P<0.0001$; Forest edges: $R^{2}=0.11, F_{1,33.4}=0.71, P=0.41$; forest interiors: $R^{2}=0.76, F_{1,42.7}=2.92, P=0.095 ;$ Fig. 3 ).

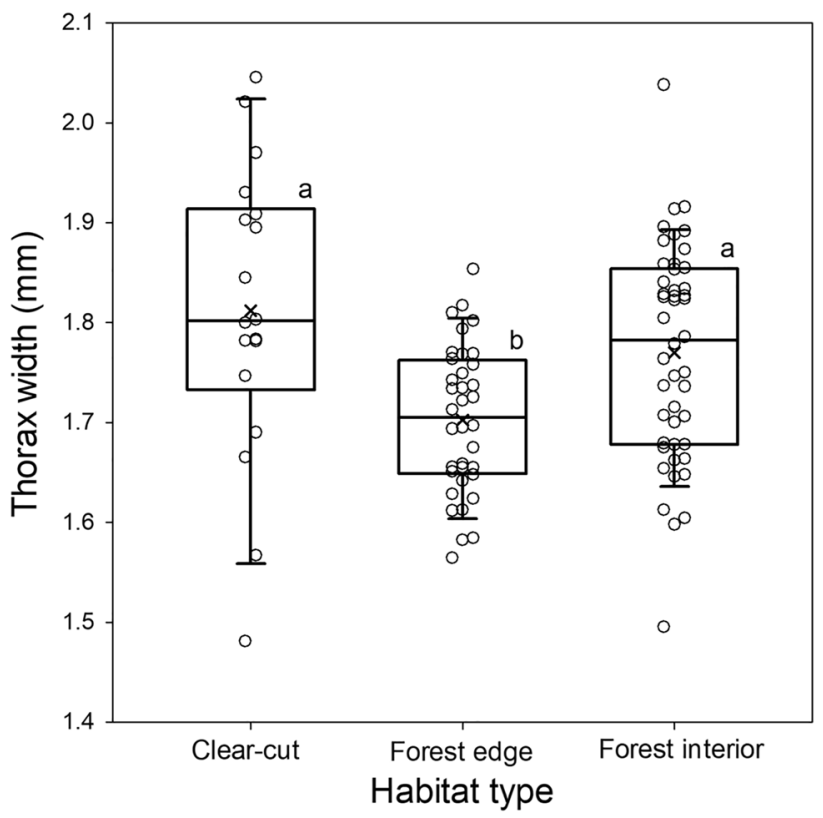

Fig. 2 Thorax width of males in clear-cuts, forest edges (clear-cut margins) and forest interiors. Data points are jittered in order to avoid overlapping. Different letter above symbols indicates significant pairwise difference (Tukey's test $P<0.05$ ) 

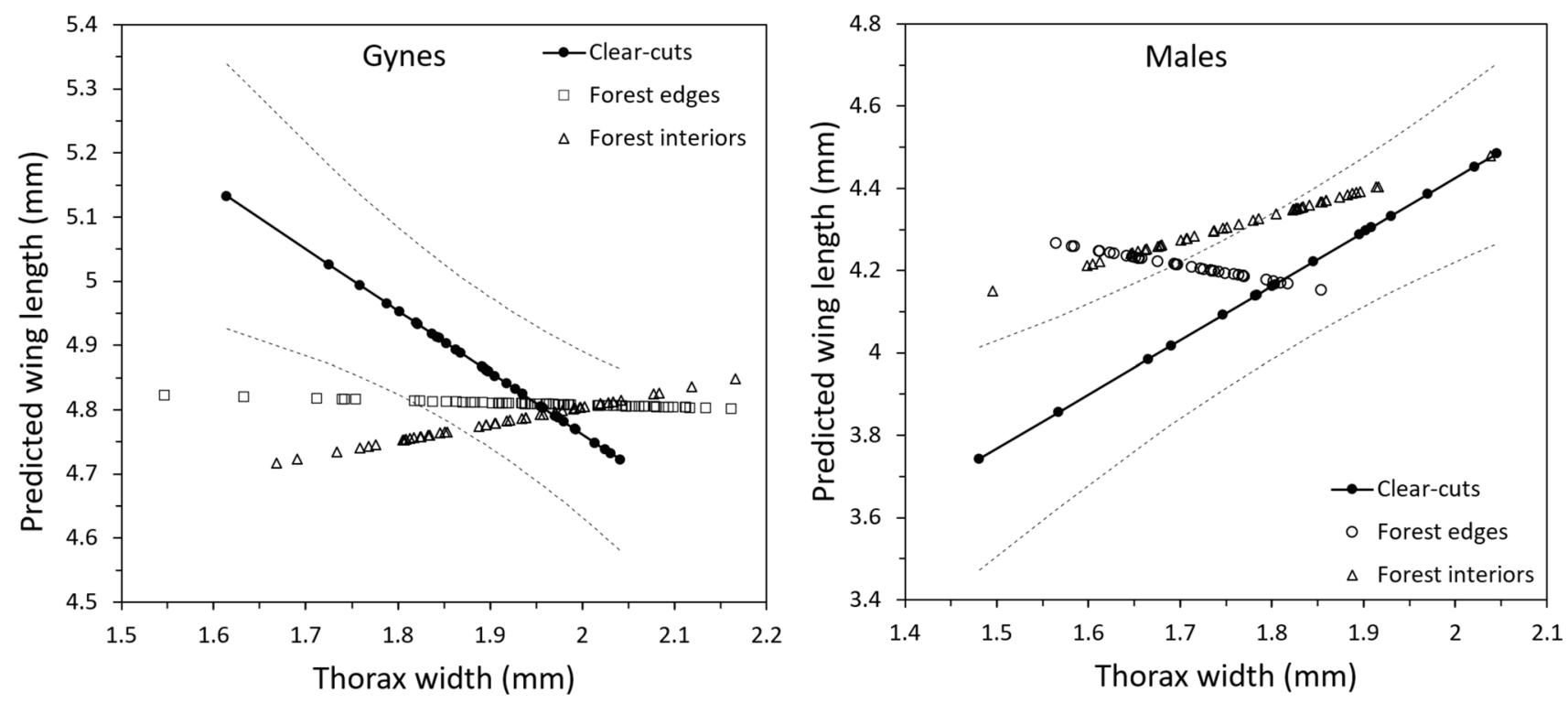

Fig. 3 Association between thorax width and wing length in gynes and males in clear-cuts, forest edges (clear-cut margins) and forest interiors. Predicted wing length values from linear mixed model, clear-cut values with predicted values $95 \%$ confidence limits

\section{Allometry}

The slopes of $\log \left(\log _{10}\right)$ ratios of HW/TW and WL/TW against TW, and WL/HW against $\mathrm{HW}$, were all negative and significantly different from zero in both gynes and males, indicating that there is allometric scaling of the shape of body parts (Table 1). The association of the slopes of log HW/TW and log WL/HW did not differ between the habitat types, but the slope log WL/TW was differently associated between the habitat types in both sexes (Table 1). Scaled with the growth of thorax width, the wing length grew less in clear-cuts that in the other habitats in gynes, whereas in
Table 1 Regression parameters for the measured morphological parameters in gynes and males of Formica aquilonia

\begin{tabular}{|c|c|c|c|c|c|c|c|c|c|}
\hline Sex & $x$ & $y$ & Habitat & log slope & $t$-value & d.f & $P$ & $r^{2}(\%)$ & Habitat interaction \\
\hline \multirow[t]{9}{*}{ Gynes } & \multirow[t]{3}{*}{$\mathrm{TW}$} & \multirow[t]{3}{*}{ HW/TW } & Clear-cuts & -1.204 & -8.39 & 33.0 & $<0.0001$ & 68.1 & $F_{2,134}=2.20$ \\
\hline & & & Forest edges & -0.892 & -12.02 & 56.9 & $<0.0001$ & 79.1 & $P=0.11$ \\
\hline & & & Forest interiors & -0.768 & -6.73 & 40.9 & $<0.0001$ & 46.7 & \\
\hline & \multirow[t]{3}{*}{ TW } & \multirow[t]{3}{*}{ WL/TW } & Clear-cuts & -1.327 & -12.61 & 31.9 & $<0.0001$ & 84.0 & $F_{2,132}=3.32$ \\
\hline & & & Forest edges & -1.023 & -13.16 & 58.3 & $<0.0001$ & 77.7 & $P=0.039$ \\
\hline & & & Forest interiors & -0.968 & -10.26 & 42.9 & $<0.0001$ & 70.3 & \\
\hline & \multirow[t]{3}{*}{ HW } & \multirow[t]{3}{*}{ WL/HW } & Clear-cuts & -0.879 & -7.31 & 29.5 & $<0.0001$ & 10.6 & $F_{2,131}=0.66$ \\
\hline & & & Forest edges & -0.654 & -4.96 & 57.5 & $<0.0001$ & 12.6 & $P=0.52$ \\
\hline & & & Forest interiors & -0.732 & -6.99 & 43.9 & $<0.0001$ & 13.8 & \\
\hline \multirow[t]{9}{*}{ Males } & \multirow[t]{3}{*}{ TW } & \multirow[t]{3}{*}{ HW/TW } & Clear-cuts & -0.346 & -2.08 & 14.2 & 0.056 & 18.6 & $F_{2,83.3}=1.85$ \\
\hline & & & Forest edges & -0.984 & -4.04 & 32.0 & 0.0003 & 36.7 & $P=0.16$ \\
\hline & & & Forest interiors & -0.664 & -3.78 & 39.4 & 0.0005 & 24.7 & \\
\hline & \multirow[t]{3}{*}{ TW } & \multirow[t]{3}{*}{ WL/TW } & Clear-cuts & -0.400 & -4.44 & 14.2 & 0.0005 & 38.3 & $F_{2,90.5}=4.62$ \\
\hline & & & Forest edges & -1.072 & -6.72 & 33.1 & $<0.0001$ & 51.8 & $P=0.012$ \\
\hline & & & Forest interiors & -0.764 & -5.26 & 42.2 & $<0.0001$ & 42.1 & \\
\hline & \multirow[t]{3}{*}{ HW } & \multirow[t]{3}{*}{ WL/HW } & Clear-cuts & -0.486 & -2.88 & 9.67 & 0.017 & 53.6 & $F_{2,86.7}=1.35$ \\
\hline & & & Forest edges & -0.825 & -6.05 & 30.7 & $<0.0001$ & 38.2 & $P=0.26$ \\
\hline & & & Forest interiors & -0.640 & -6.93 & 38.9 & $<0.0001$ & 54.8 & \\
\hline
\end{tabular}

Head width (HW) and wing length (WL) were regressed as logarithms of ratios with thorax width (TW) or HW using formula $\log y=b+a[\log (x / y)]$. In both sexes, the slopes of both HW and WL differed significantly from zero indicating size-free shape changes against the size variable (TW, or HW). Both in gynes and males, the slopes WL/TW $\times$ TW were different between habitat types 
the males, the wing length grew less in other habitats than in clear-cuts (Fig. 4).

\section{Discussion}

Our study showed that forestry-induced habitat degradation is associated with the shape of gynes and males of $F$. aquilonia but with different morphological reactions. The different allometric relationships between wing length and thorax width found in gynes and males can simply be the result of differences in developmental constraints between the sexes, which likely is due to the haploid (males) and diploid (gynes) genome that already produces clear morphological differences between ant sexes. Similarly, in both sexes the different scaling relationships between wing length and thorax width among clear-cut vs. forest colonies may be the result of developmental constraints on wing growth in resource poor environment.

Previous studies show that the production of sexual offspring may decrease significantly in clear-cut areas and the produced sex ratios are more gyne-biased (Sorvari and Hakkarainen 2005, 2007a). Thus, the developmental reactions in gynes may reflect also weaker competition between siblings in smaller broods and/or weaker competition between sexes. The ants may try in this challenging environment produce less gynes but of higher quality. An adaptive colony level strategy in clear-cuts would be producing high quality gynes and males that are able to disperse to more optimal habitats. However, based on this data long-winged gynes and males with large wing musculature (large TW) was not found more often than in other habitats. Instead, large headed gynes were common in clear-cuts, which could in some sense be a sign of quality improvement.

A mated gyne, 'a queen', of $F$. aquilonia has three options, (i) staying in the natal nest, (ii) disperse to an existing colony of conspecifics and (iii) try to establish a new colony (Rosengren and Pamilo 1983). The dispersal of individual gyne can be done either by flying or often by foot (Rosengren and Pamilo 1983). Formica aquilonia gyne is establishing new colonies via a risky temporal social parasitism route by taking over colonies of Serviformica species (e.g., Formica fusca) (Gösswald 1989; Buschinger 2009; Chernenko et al. 2013). While not shown in this species, big head and mandibles might be an advantage if it needs to fight. However, joining to conspecific colony is less risky than temporal parasitism strategy; thus, in an open area or forest edge area, such as clear-cuts, a mated gyne dispersing by foot likely seeks primarily an opportunity to join an existing conspecific colony.

The head width of queens was significantly larger in clear-cut areas than in forests, which contrasts our previous finding in the same study areas (Haatanen and Sorvari 2013). In addition, our current result differs from a previous result in related species, Formica podzolica, that showed no difference in gyne size between rich and poor-quality habitats (Deslippe and Savolainen 1994). The data for our previous study was collected in 2003, and current data two years before that in year 2001, when the logging disturbance was more recent. All nests in clear-cuts are not in equally poorly
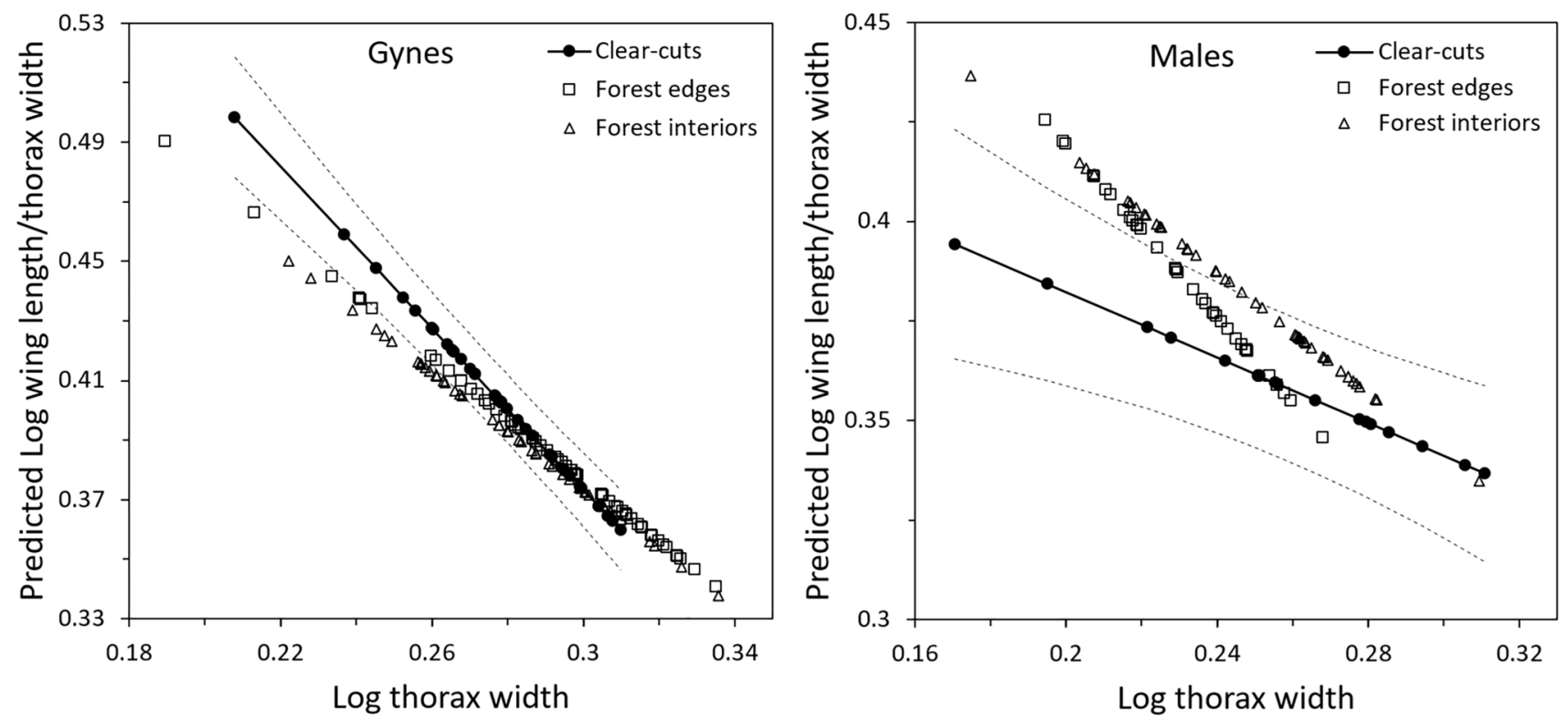

Fig. 4 Size-related change of wing length in gynes and males of $F$. aquilonia, shown in relation to thorax width in clear-cuts, forest edges (clearcut margins) and forest interiors. Predicted values from linear mixed model, clear-cut values with predicted values $95 \%$ confidence limits 
located, nests closer to remaining forests tend to reproduce and survive better than nests located in the centre of clearcut (Sorvari 2013). Therefore, it may be that the samples from the year 2003 were from nests closer to the forest edge. Another possibility is that the ants somehow adapted to the poor environment; however, this ant is highly forest-dwelling species (Punttila and Kilpeläinen 2009) as its populous colonies need rich food resources provided by forests and only its populous colonies in large nest mounds tend to produce gynes and males (Sorvari and Hakkarainen 2005).

Interestingly, the head size of gynes was not significantly associated with thorax width, at least with this range of sizes. Head width has often been used as an estimate of body size in ants, such as Formica sp. (e.g., Deslippe and Savolainen 1994; Sorvari and Hakkarainen 2009; Skaldina et al. 2018), but according to our results, its use as an estimate of gyne size may not be accurate. Thorax width may be another candidate for this, or dry body mass. Here, thorax width was not different in gynes originating in the three different habitats. Similarly, wing length of gynes was similar among the habitat types.

In males, head width increased with thorax width and did not differ between the habitats. This resembles the results of Deslippe and Savolainen (1994) where head width of $F$. podzolica males did not differ between rich and poor-quality habitats. However, thorax width was slightly smaller in forest edges compared to the other habitat types. Wing length was similar among the habitat types. For a $F$. aquilonia male, the dispersal ability by flight is essential, as it needs to seek a gyne to mate with. Slightly narrower thorax width, thus possibly weaker wing muscles, in forest edge habitat may affect the dispersal ability of those males. Since forest edge was here the intermediate-disturbance habitat, we have no strong suggestion for the reason behind the narrower thorax size.

Homozygous individuals tend to be more sensitive to environmental variation than heterozygous ones (e.g., Tomkins and Kotiaho 2002). Therefore, haploid, thus homozygous, males should be more sensitive to environmental change. However, in our study both the diploid gynes and haploid (homozygous) males showed morphological responses to habitat alteration.

Head, thorax and wings gets their final size and shape in metamorphosis in pupa; thus, they could be affected by (1) temperature regimes during pupation and (2) nutrition and temperature regimes during larval stage. Nutrition provides elements for different tissues and temperature is typically linked with development speed in insects (Chown and Nicolson 2004). In insects, such as our ants, the proportion of chitin tissues is large especially in wings; also head capsules and mandibles are rich with chitin whereas thorax has larger proportion of other tissues such as flight muscles (Gullan and Granston 2005). As the proportions of different tissue types differ between the studied body parts, it is possible that differences in nutrition and temperatures among habitat types can result in observed differences in body part sizes and shapes.

Both sexes showed allometric scaling of the measured body parts (HW, TW and WL). Interestingly, the allometric scaling of wings was different in clear-cuts than in the less disturbed habitat types in both sexes. Tschinkel et al. (2003) have shown that bodies of ant Solenopsis invicta workers are only slightly allometric, and usually allometry is strongest in the head. Similarly Breed (2002) showed that the allometry in workers of Paraponera clavata is strongest in head shape. In the present case, we studied only three measurements and, based on $t$ and $r^{2}$ values (Table 1), the wing length seems to be most allometric in gynes; whereas, in males, allometry seems to be approximately the same among measured body parts. In addition, in gynes, it seems that allometry of wing size and head width is stronger in clear-cuts and its margins (Table 1). In Breed's (2002) data on P. clavata, the magnitude of allometry varied among colonies and it was thought to be due to differences in colony maturity or colony differences in developmental patterns. In our case, all colonies were mature sexual offspring producing colonies, thus, habitat quality is the most evident candidate to cause observed differences in shapes.

While some morphological response to clear-cutting, e.g., gyne head size, may sound adaptive it surely is not an adaptation to a historically recent forest management practice but more likely to storm events and wildfires in evolutionary time scale. However, there is no studies on wood ants' reactions in storm disaster and wildfire areas. Previously in this species clear-cutting has shown to decrease production of sexual offspring, especially males (Sorvari and Hakkarainen 2005, 2007b), decreasing worker body size and body energy levels (Sorvari and Hakkarainen 2009), disturbing immunity of workers and gynes (Sorvari et al. 2008), increasing overwintering mortality (Sorvari et al. 2011), disturbing nest temperature and moisture regulation (Sorvari and Hakkarainen 2009; Sorvari et al. 2016) and finally causing abandonment of nest mounds (Sorvari and Hakkarainen 2007a).

To conclude, forest logging as a habitat degradation for a forest-dwelling ant is associated with disproportionate growth of body parts and the allometry in wings was different in logged habitat than in the less disturbed habitats. To our knowledge, this is the first observation of habitat difference-related allometric scaling in insects.

Supplementary Information The online version contains supplementary material available at https://doi.org/10.1007/s00040-021-00846-0.

Acknowledgements T. van Ooik and O. Skaldina helped in the field and the laboratory. An earlier version of the manuscript was improved by the constructive comments from two anonymous reviewers. 
Author contributions JS collected the field data and made the statistical analyses. MKH took photographs and morphological measurements. JS wrote the first draft of the manuscript, MKH provided comments and further editions to the manuscript.

Funding Open Access funding provided by University of Turku (UTU) including Turku University Central Hospital. Emil Aaltonen foundation (JS), the Kone Foundation (JS), the Finnish Cultural Foundation $(\mathrm{MKH})$, the Entomological Society of Finland (MKH) and the Turku University Foundation (MKH).

Availability of data The data is available from the corresponding author upon request.

Code availability Not applicable.

\section{Declarations}

Conflict of interest The authors declare no conflict of interest.

Ethical approval Not applicable.

Consent to participate Not applicable.

Consent to publication Not applicable.

Open Access This article is licensed under a Creative Commons Attribution 4.0 International License, which permits use, sharing, adaptation, distribution and reproduction in any medium or format, as long as you give appropriate credit to the original author(s) and the source, provide a link to the Creative Commons licence, and indicate if changes were made. The images or other third party material in this article are included in the article's Creative Commons licence, unless indicated otherwise in a credit line to the material. If material is not included in the article's Creative Commons licence and your intended use is not permitted by statutory regulation or exceeds the permitted use, you will need to obtain permission directly from the copyright holder. To view a copy of this licence, visit http://creativecommons.org/licenses/by/4.0/.

\section{References}

Araujo MB, Tschinkel WR (2010) Worker allometry in relation to colony size and social form in the fire ant Solenopsis invicta. J Insect Sci 10:94. https://doi.org/10.1673/031.010.9401

Breed MD (2002) Allometry in the giant tropical ant, Paraponera clavata. Insect Soc 49:125-128

Buschinger A (2009) Social parasitism among ants: a review (Hymenoptera: Formicidae). Myrmecol News 12:219-235

Chernenko A, Vidal-Garcia M, Helanterä H, Sundström L (2013) Colony take-over and brood survival in temporary social parasites of the ant genus Formica. Behav Ecol Sociobiol 67:727-735

Chown SL, Nicolson SW (2004) Insect physiological ecology: mechanisms and patterns. Oxford University Press, New York

Collingwood CA (1979) The Formicidae (Hymenoptera) of Fennoscandia and Denmark. Fauna Entomol Scand 8:9-179

Deslippe RJ, Savolainen R (1994) Role of food supply in structuring a population of Formica ants. J Anim Ecol 63:756-764

Feener DH, Lighton JRB, Bartholomew GA (1988) Curvilinear allometry, energetics and foraging ecology: a comparison of leaf-cutting ants and army ants. Funct Ecol 2:509-520
Gösswald K (1989) Die Waldameise. Band 1. Biologische Grundlagen, Ökologie und Verhalten. AULA-Verlag, Wiesbaden

Grześ IM, Okrutniak M, Szpila P (2015) Fluctuating asymmetry of the yellow meadow ant along a metal-pollution gradient. Pedobiologia 58:195-200. https://doi.org/10.1016/j.pedobi.2015.11. 001

Gullan PJ, Granston PS (2005) The Insects - an outline of entomology, 3rd edn. Blackwell, Oxford

Haatanen M-K, Sorvari J (2013) Similarity of body size in queens of the wood ant Formica aquilonia from optimal and sub-optimal habitats may indicate a heritable component. J Insect Sci 13:115

Ivanković Tatalović L, Anđelić B, Jelić M, Kos T, Benítez HA, Šerić Jelaska L (2020) Fluctuating asymmetry as a method of assessing environmental stress in two predatory carabid species within Mediterranean agroecosystems. Symmetry 12:1890. https://doi. org/10.3390/sym 12111890

Keenan RJ, Kimmins JP (1993) The ecological effects of clear-cutting. Environ Rev 1(2):121-144

Koyama T, Mendes CC, Mirth CK (2013) Mechanisms regulating nutrition-dependent developmental plasticity through organspecific effects in insects. Front Physiol 4:263. https://doi.org/ 10.3389/fphys.2013.00263

Kvamme T (1982) Atlas of the Formicidae of Norway (Hymenoptera: Aculeata). Insecta Norvegiae 2:1-56

Lavine L, Gotoh H, Brent CS, Dworkin I, Emlen DJ (2015) Exaggerated trait growth in insects. Annu Rev Entomol 60:453-472. https://doi.org/10.1146/annurev-ento-010814-021045

Lenoir L (2003) Response of the foraging behaviour of red wood ants (Formica rufa group) to exclusion from trees. Agric For Entomol 5:183-189. https://doi.org/10.1046/j.1461-9563.2003. 00176.x

Mosiman J, James F (1979) New statistical methods for allometry with application to Florida red-winged blackbirds. Evolution 33:444-459

Nunes LA, de Araújo ED, Marchini LC (2015) Fluctuating asymmetry in Apis mellifera (Hymenoptera: Apidae) as bioindicator of anthropogenic environments. Rev Biol Trop 63(3):673-682

Pamilo P (1982) Genetic population structure in polygynous Formica ants. Heredity 48:95-106

Punttila P, Kilpeläinen J (2009) Distribution of mound-building ant species (Formica spp., Hymenoptera) in Finland: preliminary results of a national survey. Ann Zool Fennici 46:1-15

Rabitsch WB (1997) Levels of asymmetry in Formica pratensis Retz. (Hymenoptera, Insecta) from a chronic metal-contaminated site. Environ Toxicol Chem 16:1433-1440

Rosengren R, Pamilo P (1983) The evolution of polygyny and polydomy in mound-building Formica ants. Acta Entomol Fennica 42:65-77

Skaldina O, Sorvari J (2017) Wood ant colouration as an ecological indicator for the level of disturbance in managed coniferous forests. Ecol Indic 72:444-451. https://doi.org/10.1016/j.ecoli nd.2016.08.039

Skaldina O, Peräniemi S, Sorvari J (2018) Ants and their nests as indicators for industrial heavy metal contamination. Environ Pollut 240:574-581. https://doi.org/10.1016/j.envpol.2018.04. 134

Skaldina O, Ciszek R, Peräniemi S, Kolehmainen M, Sorvari J (2020) Facing the threat: common yellowjacket wasps as indicators of metal contamination. Environ Sci Pollut Res 27:2903129042. https://doi.org/10.1007/s11356-020-09107-2

Sorvari J (2013) Proximity to the forest edge affects the production of sexual offspring and colony survival in the red wood ant Formica aquilonia in forest clear-cuts. Scand J For Res 28:451-455

Sorvari J (2021) Distribution of Finnish mound-building Formica ants (Hymenoptera: Formicidae) based on using a citizen science approach. Eur J Entomol 118:57-62 
Sorvari J, Hakkarainen H (2005) Deforestation reduces nest mound size and decreases the production of sexual offspring in the wood ant Formica aquilonia. Ann Zool Fennici 42:259-267

Sorvari J, Hakkarainen H (2007) Forest clearing and sex ratio in forest-dwelling wood ant Formica aquilonia. Naturwissenschaften 94:392-395

Sorvari J, Hakkarainen H (2007) Wood ants are wood ants: deforestation causes population declines in the polydomous wood ant Formica aquilonia. Ecol Entomol 32:707-711

Sorvari J, Hakkarainen H (2009) Forest clear-cutting causes small workers in the polydomous wood ant Formica aquilonia. Ann Zool Fennici 46:431-438

Sorvari J, Hakkarainen H, Rantala MJ (2008) Immune defense of ants is associated with changes in habitat characteristics. Environ Entomol 37:51-56
Sorvari J, Haatanen M-K, Vesterlund S-R (2011) Combined effects of overwintering temperature and habitat degradation on the survival of boreal wood ant. J Insect Conserv 15:727-731. https://doi.org/10.1007/s10841-010-9372-5

Sorvari J, Elo RA, Härkönen SK (2016) Forest-built nest mounds of red wood ant Formica aquilonia are no good in clear fells. Appl Soil Ecol 101:101-106. https://doi.org/10.1016/j.apsoil. 2016.01.019

Tomkins JL, Kotiaho JS (2002) Fluctuating Asymmetry. In: eLS. John Wiley \& Sons Ltd, Chichester. http://www.els.net. https://doi.org/ 10.1038/npg.els.0003741

Tschinkel WR, Mikheyev AS, Storz SR (2003) Allometry of workers of the fire ant Solenopsis invicta. J Insect Sci 3:2

Vaahtera E (2019) Silviculture. In: Peltola A (ed) Finnish forest statistics. Luonnonvarakeskus, Helsinki, pp 59-76 